\title{
LIZINNI, Olga. Fluxus. Indagine sui fondamenti della metafisica e della física di Avicena. Bari: Edizioni di pagina, 2011, 679p. ISBN 978-88-7470-123-0.
}

Olga Lizinni apresenta nesta obra uma análise da Metafísica do Livro da Cura (Kitāb al-Sifā) de Avicena, rastreada à luz do conceito fundamental de fluxo (fayd). Arabista e Doutora em Filosofia, Lizzini preparou, juntamente com Pasquale Porro, a primeira edição italiana da Metafísica de Avicena (Ed. Trilingue: árabe, latim, italiano. Milão 2002; ${ }^{2} 2006$ ). A obra que publica agora sobre o conceito de fluxus (fayḍ) é reveladora de uma análise feita a partir do conhecimento intrínseco da língua árabe. É a partir do trabalho filológico que Lizzini desbrava a centralidade do conceito de fluxus quer na Metafísica de Avicena, quer em outras obras do filósofo árabe.

Essa volumosa obra de Lizzini está dividida em cinco capítulos, aos quais se seguem dois Apêndices, uma Bibliografia, um Índice de lugares citados e, finalmente, um Índice de autores. O capítulo primeiro, Fluxo, fluir, fazer fluir - fayḍ, fayaḍān, ifāọa (p. 27-87), expõe as "primeiras notas sobre a terminologia do fluxo". Trata-se de um levantamento de ocorrências do termo quer nos textos neoplatônicos traduzidos para o árabe pelo círculo de Al-Kindi (Plotiniana árabe: respectivamente a obra Teologia pseudo-aristotélica, a Epístola sobre a Ciência Divina e os Ditos do Sábio Grego; Procliana árabe: Elementatio Theologica e Discurso ou Livro do Sumo Bem), quer nas obras de autores que precederam Avicena, nomeadamente $\mathrm{Al}$-Kindi e Al-Farabi, recolhendo ainda algumas primeiras observações sobre o tratamento aviceniano de fluxus. O Capítulo 2 parte da definição de fayd dada por Avicena no Livro das definições (Kitāb al-Hudūd), para evidenciar o alcance metafísico do termo e as questões que lhe são subsequentes. O termo fluxo é empregue para referir a procedência do mundo em relação ao Primeiro Principio ou para dar conta das aporias, de âmbito lógico-linguístico e ontológico, que envolvem essa procedência. O absoluto primado do Primeiro e a Necessidade da sua existência limitam desde logo a sua dizibilidade e compreensão. Por isso, tratar dos atributos de Deus significa considerar a derivação do mundo

\begin{tabular}{|l|l|l|l|l|l|}
\hline Veritas & Porto Alegre & v. 57 & n. 2 & maio/ago. 2012 & p. 216-220 \\
\hline
\end{tabular}


e, inversamente, qualificar a emanação de algo a partir de Deus implica necessariamente adscrever atributos ao próprio Deus. Escreve Lizzini: "Qualunque predicazione che vada al di là della mera esistenza di Dio implica il mondo e con esso il flusso che gli dà origine; la predicazione degli attributi divini finisce così per coincidere con lo stesso flusso" (p. 94). A questão é a de saber de que modo é possível a predicação de Deus e se esta é de fato uma predicação dele ou do que flui a partir dele. Dada a inefabilidade absoluta de Deus, Avicena considera que o silêncio, mais do que o discurso negativo ou afirmativo, é a resposta coerente ao problema da predicação do divino. A relação do Necessariamente Existente com o mundo coloca-se não a partir do próprio Primeiro, mas a partir da procura da razão última da relação que todos os existentes têm entre si. Ora, a temática do fluxo é operativa na metafisica aviceniana, precisamente para compreender essa relação. Trata-se de uma relação irrecíproca, sem correlação: “ È al interno di questo orizzonte dottrinale che le relazioni possano andare ascritte al Necessariamente Esistente: pensate como non costituenti l'essenza del Principio e rispetto ad essa esterne, esse sono causate dall'essenza del Principio e le sono posteriori, come posteriori al Primo è lo stesso flusso d'essere che da Esso si origina" (p. 97). A ideia de fluxo é por conseguinte central na compreensão da relação de Deus com o Mundo, do problema aviceniano da emanação, da identificação dos modos do existente, da instauração do mundo ou da resolução do problema da sua origem, para a compreensão da identidade de Deus e dos existentes e para o estabelecimento da diferença ontológica. Essas são, em síntese, as grandes questões sob as quais a análise do conceito de fluxo e a sua operatividade no sistema aviceniano pretende lançar luz. No que diz respeito ao Livro das Definições, conclui a autora, três são os aspectos desta doutrina que aí se evidenciam: a necessidade do fluxo, o seu caráter ontológico e o seu carácter hierárquico (p. 109). Essas características serão explicitadas e os seus conteúdos serão determinados na Metafísica do Livro da Cura. Nesta obra, a relação é analisada em termos de causalidade e, de modo particular, a partir da diferença entre o Existente Necessário e o Possível. Partindo da consideração aviceniana do fluxo como "causalidade comunicável" (p. 114), a autora explana três temas centrais da metafísica aviceniana: a relação necessidade-possibilidade (p. 114-146); a relação essência-existência (p. 147-157) e a relação de providência, no horizonte do conceito de "utilidade" em que Avicena a inscreve (p. 193-223). Lizzini leva a cabo uma verdadeira exposição da ontologia aviceniana: a noção de fluxo serve-lhe aqui de ponto de partida, mas as questões são discutidas em um horizonte que ultrapassa a delimitação do conceito em causa. A análise sobre a relação entre necessidade e possibilidade mostra bem a 
função heurística que essa disjunção assume na ontologia aviceniana, concretamente na concepção do existente causado (necessário por outro) e da sua relação com o Necessariamente existente. Completa essa análise o esclarecimento da estrutura ontológica do existente entre essência e existência, da diferença entre ambos os princípios e do primado da essência sobre a existência. Um último apartado do Capítulo II é dedicado à delimitação do termo fluxo: "ci usa soltanto a proposito del Creatore e delle Inteligenze" (p. 224-234). Desse modo, a autora introduz as temáticas dos três capítulos seguintes, nos quais trata respectivamente o problema do "agir divino" (Capítulo 3), a emanação do mundo sublunar (Capítulo 4) e finalmente o fluxo no mundo natural ou físico (Capítulo 4).

O Capítulo 3 analisa o primeiro momento do fluxo, isto é, a emanação do existente possível a partir do necessário, mostrando como para Avicena "la causalità del Primo non è né per volontá né per elezione, ma perchè al Primo deve essere attribuito un atto assoluto (...) per il quale neppure il termine di 'instaurazione' puè essere acolto senza essere redifinito" (p. 235-236). A questão em análise é a do modo de emanação das Inteligências e dos existentes a partir do Primeiro Principio ou, como nota a autora, a da resposta aviceniana à ideia teológica de criação. Nesse âmbito, discute o preciso conceito de creatio ex nihilo em Al-Kindi e em Al-Farabi (p. 248-257) e a sua limitação na ontologia emanacionista de Avicena (p. 257-270), bem como a erradicação de toda a consistência ontológica operada pelo filósofo árabe com respeito à noção de nihil. Dessa análise evidencia-se a concepção de Avicena de instauração, como aquela que corresponde a um poder absoluto de constituir algo no ser, cuja causa é o Primeiro Principio, sem qualquer mediação por um lado (é absoluto) e sem qualquer intencionalidade por outro (é necessário). Nos dois apartados que completam esse capítulo, Lizzini analisa a dimensão ética da instauração (a emanação a partir do supremo bem ou a necessária difusibilidade dele, e o lugar possível para a consideração da vontade no Primeiro) e a dimensão noética do mesmo. Fica assim delineada a mundividência aviceniana, nos seus fundamentos ontológicos, éticos, noéticos, com base na operatividade de noção de fluxo. Nos Capítulos 4 e 5, Lizzini analisa respectivamente o devir do mundo sublunar e o fluxo no mundo físico. No que se refere ao mundo sublunar, evidencia a condição universal do fluxo e a particularidade do mundo e analisa os elementos de conciliação entre ambos, com base no modo como Avicena considera a relação entre os princípios constituintes do existente - matéria e forma - e o modelo de causalidade que lhe está subjacente. Admitindo o caráter receptivo da matéria com relação ao princípio formal - e por conseguinte admitindo a necessidade do fluxo -, Avicena considera, contudo, que a forma não tem causalidade exclusiva, 
com relação à matéria (p. 378). Avicena revê o esquema causal aristotélico, dando lugar à intervenção de um "princípio separado" de causalidade vertical (p. 381). Nessa estrutura de causalidade e na interdependência entre fluxo e influxo se inscreve a cosmologia aviceniana determinista e a explicação para o mal, temas analisados no final deste capítulo (p. 451483) e ainda o longo do capítulo quinto e último, bem como a sua relação com a questão do acaso (p. 514-542). O Capítulo 5 analisa a concepção aviceniana de natureza. Ao introduzir de uma causalidade celeste ou de um princípio "oltre che naturale" no processo de derivação das formas a partir do Primeiro, Avicena pretende abarcar no conceito de natureza toda a realidade, mesmo aquela que pode ocorrer de modo "supranatural". Com base na análise desse conceito amplo de natura (țabīa) a que se segue o apartado sobre o lugar do acaso, do determinismo e do influxo no âmbito da Física de Avicena, encerra-se a parte expositiva desta obra. Seguem-se dois Anexos. O Anexo I - Terminologia contém um léxico que esclarece um conjunto de termos implicados no campo semântico da noção de fluxus (fayḍ), tais como emanar e influir (p. 546-570) e criação, instauração e produção (p. 570-581). O Anexo II - Tavola delle opere (p. 583-595) disponibiliza uma cronologia das obras de Avicena, determinada com base em uma investigação exaustiva das fontes disponíveis, cujo objetivo é resolver as ambiguidades que se verificam sobre esse assunto. A obra contém ainda uma Bibliografia, subdividida em $I$. Fonti ed edizioni utilizzate (para as obras gregas; obras gregas e do Pseudo-Aristóteles em tradução árabe; obras latinas e obras filosóficas e teológicas árabes; e II. Leterattura secondaria (repertórios bibliográficos sobre o corpus aviceniano, Dicionários e Estudos). Finalmente, a obra apresenta um conjunto de índices de autores (antigos; árabes, hebreus, persas e sírios; autores de áreas medievais e modernos; especialistas).

Esse extenso e denso volume de Lizzini revela a competência da autora enquanto arabista e especialista em Avicena, e é o resultado de uma imensa investigação realizada em torno da metafísica aviceniana, em todos os domínios: levantamento de fontes, abordagem históricofilológica e genética dos conceitos implicados (fluxus e os referentes ao mesmo campo semântico), recolha da literatura secundária desde os inícios do século 20 até à literatura mais recente, leitura e comentário das principais teses em debate e das posições dos especialistas na área, sobretudo dos mais recentes.

A dispensação, em Anexo, dos instrumentos lexicais e a cronologia para a obra de Avicena, junto com as edições críticas e traduções disponíveis, são dois instrumentos de trabalho que, em domínios diferentes - conceitual e bibliográfico -, facilitam a continuidade da investigação nessa área. Este estudo esclarece a identidade e a originalidade da 
filosofia de Avicena e permite compreender melhor as influências por ele sofridas do pensamento grego tardo-antigo e a assimilação das teses de Avicena por parte dos medievais no Ocidente. É sem dúvida uma obra de referência incontornável no estudo da gênese e estrutura da filosofia de Avicena e da sua influência na Idade Média ocidental.

Paula Oliveira e Silva Instituto de Filosofia Universidade do Porto

Recebido em 23/05/2012.

Aprovado para publicação em 25/05/2012. 